\title{
Problem hydromorphic soils in north-east Thailand. 2. Physical and chemical aspects, mineralogy and genesis
}

\author{
Robert Brinkman \\ Department of Soil Science and Geology, Agricultural University, Duivendaal 10, \\ Wageningen, Netherlands
}

Accepted: 28 March 1977

Key words: paddy soils, interlayering, kaolinite dissolution

\section{Summary}

The genesis of one of the main soils on the extensive seasonally wet, low terrace in north-east Thailand was studied and its mineralogy and some physical and chemical aspects described.

The Roi Et soil is a silt loam with low clay contents in the surface horizon, increasing with depth. It is seasonally water-saturated, seasonally dry; has considerable porosity, but has a dense ploughpan at about $0.2 \mathrm{~m}$ and a dense substratum below $1.4 \mathrm{~m}$ depth. The soil is strongly acid with a low base saturation and a very low cation exchange capacity.

Silt and sand are $98 \%$ quartz. Disordered kaolinite is the main clay mineral. About a fifth of the clay fraction is soil chlorite: a strongly Al-interlayered vermiculite in the upper horizons but partially Al-interlayered in the substratum. The interlayers contain a small amount of ferrous iron. Quartz contents in the clay fractions range from one tenth in most of the profile to about three tenths in the surface horizon, with a corresponding decrease in kaolinite. The kaolinite in the upper horizons shows signs of dissolution.

These data are in accordance with the hypotheses of clay eluviation-illuviation and long-continued iron redistribution and ferrolysis: clay alteration and dissolution under the influence of alternating reduction and oxidation of iron.

\section{Introduction}

The environment and the soil morphology of the Roi Et soil, one of the main soils on the extensive seasonally wet, low terrace in north-east Thailand, were described earlier (Brinkman et al., 1977). This paper deals with some physical and chemical aspects, mineralogy and genesis of the Roi Et soil. A subsequent paper (Brinkman \& Dieleman, 1977) discusses the saline-acid conditions occurring on the low terrace, and possible ways of reclamation, improvement and management for irrigated double cropping. 


\section{Methods}

Bulk density and field moisture content were measured on undisturbed cores; porosity was calculated assuming a particle density of $2.65 \mathrm{~g} / \mathrm{cm}^{3}$. Particle size distribution was determined by sieve and pipette. $\mathrm{pH}$ was measured by glass electrode in suspensions $1: 2.5$ in water and $0.01 \mathrm{M} \mathrm{CaCl}_{2}$.

Organic carbon was estimated by heated dichromate-sulphuric acid, assuming $87 \%$ recovery, according to Schollenberger (1927). Exchangeable bases and cation exchange capacity (CEC) were determined by Li EDTA (Begheyn \& van Schuylenborgh, 1971); $\mathrm{Al}$ and $\mathrm{H}$ by $\mathrm{KCl}$ extraction. $\mathrm{Na}$ and $\mathrm{K}$ were measured by flame photometer and $\mathrm{Ca}, \mathrm{Mg}$ and $\mathrm{Al}$ by colorimeter.

Clay fraction pretreatment was by hot $10 \% \mathrm{H}_{2} \mathrm{O}_{2}$ buffered at $\mathrm{pH} 5$ with sodium acetate-acetic acid, followed by centrifuging and decantation of the clear supernatant. After dispersion by $\mathrm{NaOH}$ to $\mathrm{pH} \mathrm{7,} \mathrm{two} \mathrm{decantations} \mathrm{were} \mathrm{made} \mathrm{of} \mathrm{the}$ fraction $<2 \mu \mathrm{m}$.

Suspensions with about $10 \mathrm{mg} \mathrm{Na-clay} \mathrm{were} \mathrm{brought} \mathrm{on} \mathrm{porous} \mathrm{tiles} \mathrm{for} \mathrm{X-ray}$ diffraction by a suction technique according to van Reeuwijk (1976), modified from Dümmler \& Schroeder (1965). The remainder of the clay was flocculated with $\mathrm{BaCl}_{2}$, centrifuge-washed and freeze-dried for chemical analysis.

Total chemical analyses for most elements were made by X-ray fluorescence on $\mathrm{Li}_{2} \mathrm{~B}_{4} \mathrm{O}_{7}$ glass disks according to Halma (1973). Na was determined by flame photometer, ferric and ferrous iron by colorimeter after one minute decomposition by $\mathrm{HF}-\mathrm{H}_{2} \mathrm{SO}_{4}$. This time suffices for complete dissolution of these elements from the clay fractions and avoids problems of iron reduction or oxidation (Brinkman, 1977).

Heavy minerals from sand fractions were separated by bromoform and identified by petrographic microscope; feldspar counts were made on 800-2000 grains after etching by HF vapour and staining according to van der Plas (1966). Epinorm mineral calculations were made by a computer programme based on Burri (1964). Diffractograms were produced of $\mathrm{Mg}$-saturated oriented aggregates of clay fractions without and with glycerol solvation, and of $\mathrm{K}$-saturated aggregates after drying and heating to different temperatures, on a Philips PW 1050 diffractometer with $\mathrm{CoK} \alpha$ radiation, slits $1^{\circ}-0.2 \mathrm{~mm}-1^{\circ}$, Fe filter, scanning speed $1^{\circ} 20 / \mathrm{min}$, scintillation counter, time constant $4 \mathrm{~s}$, recorder range $1000 \mathrm{cycles} / \mathrm{s}$, speed $10 \mathrm{~mm} / \mathrm{min}$. Transmission electron micrographs of clay fractions were made on a Philips EM 300 electron microscope.

\section{Physical and chemical data}

The bulk density of the ploughed layer and the Eg and $\mathrm{Bg} 1$ horizons ranges about $1.4-1.45 \mathrm{~g} / \mathrm{cm}^{3}$. The ploughpan and the $\mathrm{Bg}$ horizons below $1 \mathrm{~m}$ depth have bulk densities about $1.55 \mathrm{~g} / \mathrm{cm}^{3}$ (Table 1). These differences correlate with the amount of fine tubular pores estimated in the field, suggesting that the Apg2 and particularly the $\mathrm{Bg} 3$, from $1.4 \mathrm{~m}$ down, are the main horizons restricting permeability. USBR (Anon., 1971) lists permeabilities ranging between essentially zero and $36 \mathrm{~mm} /$ day

Neth. J. agric. Sci. 25 (1977) 


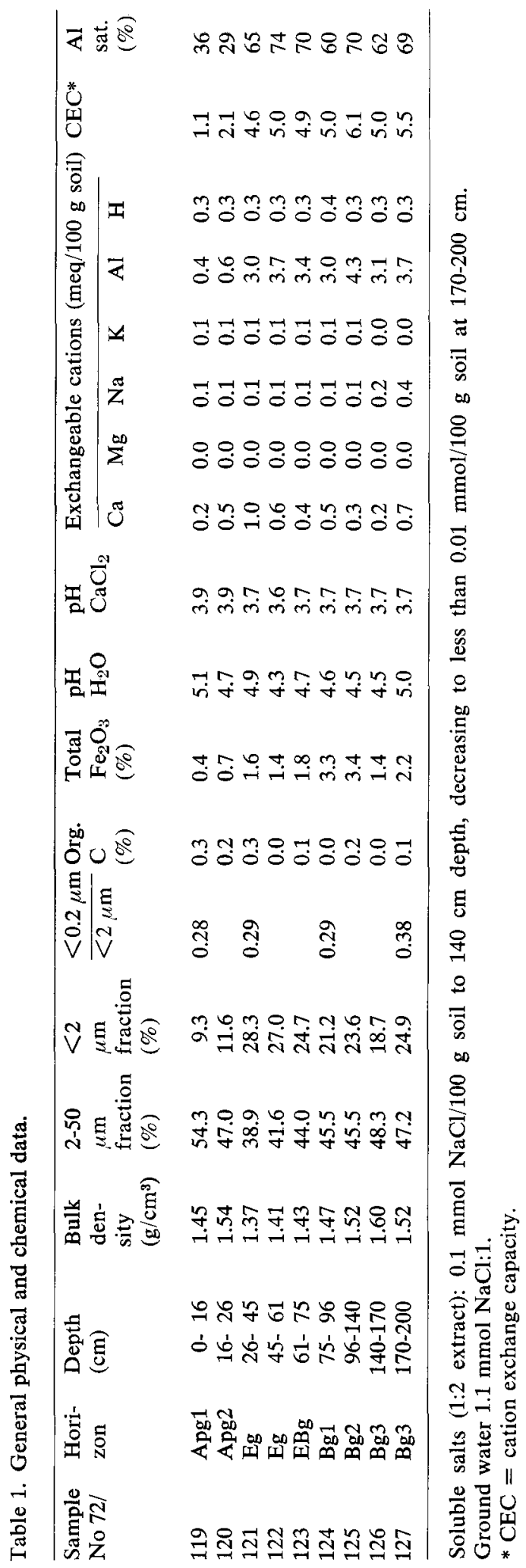


below $2 \mathrm{~m}$ depth, and ranging up to about $150 \mathrm{~mm}$ /day at shallower depths in two profiles of Roi Et series.

The moisture distribution at the end of the dry season (Fig. 1) indicates that moisture contents are virtually constant throughout the Bg horizons and steadily decrease in the upper horizons toward the surface. Moisture depletion in the dry season apparently extends to about $0.7 \mathrm{~m}$ depth under one unirrigated rice crop per year.

The grain size distribution was recalculated to (sand + silt) fractions total $100 \%$ (Fig. 2), in order to separate the possible effects of clay redistribution and decomposition from sedimentary differences. The homogeneity of the sand and silt fractions throughout the profile is evident. In contrast, the clay content is low in the Apg horizons, rises abruptly to a maximum in the upper Eg horizon and decreases slightly toward the $\mathrm{Bg}$ horizons. The low clay contents in the surface horizons appear systematic, but not the maximum in the Eg horizon: one of the two Roi Et profiles reported on by USBR (Anon., 1971) lacks this maximum and is homogeneous below the Ap horizons, the other has a maximum but has corre-

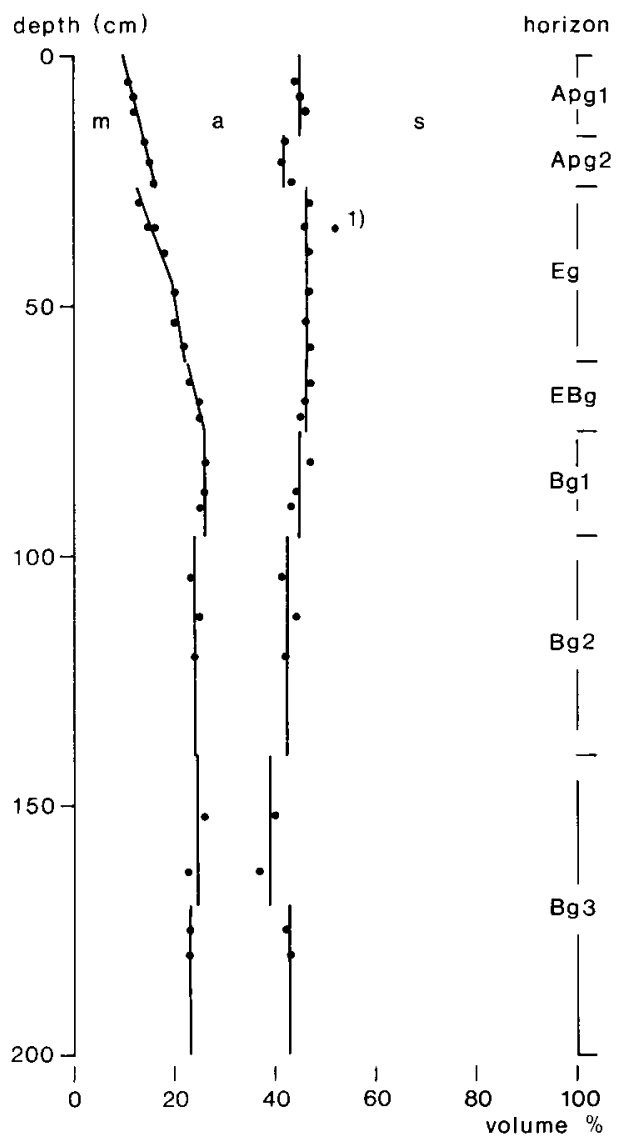

Fig. 1. Moisture distribution and total porosity. $\mathrm{m}=$ field moisture (February: late dry season); $\mathrm{a}=$ air; $\mathrm{s}=$ solids (density $2.65 \mathrm{~g} /$ $\mathrm{cm}^{3}$ assumed).

${ }^{1}$ Sample contains large pore. 

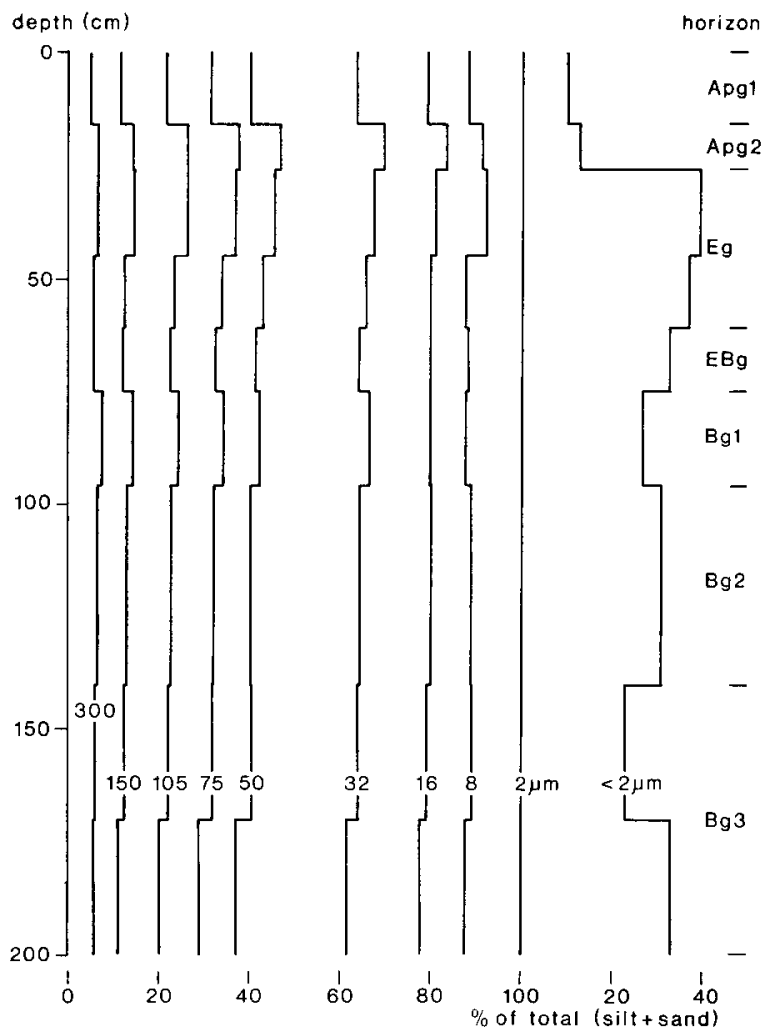

Fig. 2. Cumulative grain size distribution, recalculated to (sand + silt) fractions (total $100 \%$ ).

sponding variations in the coarse fractions with depth. The ratio of fine clay $(<0.2 \mu \mathrm{m})$ to total clay is 0.38 in the lowest horizons and $0.29-0.28$ in the remainder of the profile. This suggests that other soil forming processes may have superseded clay translocation, as also indicated by the micromorphological data.

The profile has a low organic matter content, a low $\mathrm{pH}$, a very low cation exchange capacity particularly in the Apg horizons, and a high proportion of exchangeable aluminium especially in the $\mathrm{Eg}$ and $\mathrm{Bg}$ horizons (Table 1).

The variation in total chemical composition (not listed) is almost completely due to the variations in clay content and composition. The fraction coarser than $2 \mu \mathrm{m}$ is $99 \% \mathrm{SiO}_{2}$.

The chemical composition of the clay fraction (Table 2 ) is relatively constant in the $\mathrm{Bg}$ and $\mathrm{Eg}$ horizons, but $\mathrm{SiO}_{2}, \mathrm{TiO}_{2}, \mathrm{FeO}$ and $\mathrm{P}_{2} \mathrm{O}_{5}$ contents increase in the Apg horizons whereas $\mathrm{Al}_{2} \mathrm{O}_{3}, \mathrm{Fe}_{2} \mathrm{O}_{3}, \mathrm{MgO}$ and $\mathrm{K}_{2} \mathrm{O}$ tend to decrease.

The cation exchange capacity of the clay fractions was estimated in several ways. For each sample, the CEC of the fine earth (includng organic matter) was recalculated on the basis of $100 \mathrm{~g}$ clay and plotted on the ordinate, and the organic carbon percentage, likewise recalculated per $100 \mathrm{~g}$ clay, on the abscissa (Fig. 3). If the clay and organic matter in a soil profile would have a constant CEC, such 
Table 2. Total chemical composition of clay fractions (\% w/w).

\begin{tabular}{|c|c|c|c|c|c|c|c|c|c|c|c|c|c|}
\hline \multicolumn{2}{|c|}{$\begin{array}{l}\mathrm{Sam}-\mathrm{SiO}_{2} \\
\text { ple } \\
\text { No } 72 /\end{array}$} & \multicolumn{3}{|c|}{$\mathrm{Al}_{2} \mathrm{O}_{3} \mathrm{Fe}_{2} \mathrm{O}_{3} \mathrm{FeO}$} & $\mathrm{MnO}$ & $\mathrm{MgO}$ & $\mathrm{CaO}$ & $\mathrm{Na}_{2} \mathrm{O}$ & $\mathrm{K}_{2} \mathrm{O}$ & $\mathrm{TiO}_{2}$ & $\mathrm{P}_{2} \mathrm{O}_{5}$ & $\mathrm{BaO}^{*}$ & $\begin{array}{l}\text { Ign. } \\
\text { loss }\end{array}$ \\
\hline 119 & 61.6 & 21.7 & 2.32 & 0.12 & 0.01 & 0.21 & 0.08 & 0.09 & 0.31 & 2.31 & 0.12 & 1.39 & 9.9 \\
\hline 121 & 50.1 & 30.5 & 3.27 & 0.10 & 0.01 & 0.22 & 0.07 & 0.09 & 0.29 & 1.63 & 0.05 & 1.67 & 12.1 \\
\hline 124 & 49.1 & 30.2 & 4.74 & 0.09 & 0.00 & 0.25 & 0.07 & 0.09 & 0.44 & 1.53 & 0.05 & 1.77 & 12.0 \\
\hline 127 & 48.7 & 29.9 & 5.53 & 0.08 & 0.00 & 0.22 & 0.07 & 0.09 & 0.41 & 1.50 & 0.05 & 1.85 & 11.8 \\
\hline
\end{tabular}

* Clay fractions are Ba-saturated.

a diagram would consist of a straight line, the (positive) slope of which indicates the CEC per gramme organic carbon, and the intercept with the ordinate the CEC of the clay fraction. It is clear from Fig. 3 that the clay fractions of the upper horizons have a lower cation exchange capacity than those of the horizons at greater depths, regardless of the CEC ascribed to the organic matter. Data on clay fractions

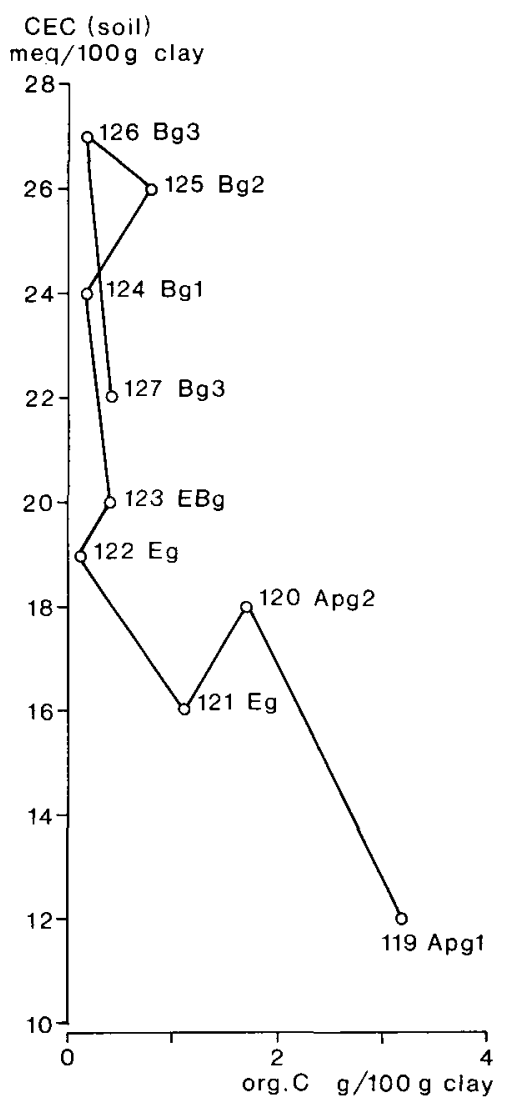

Fig. 3. Cation exchange capacity of soil, recalculated per $100 \mathrm{~g}$ clay. Abscissa: organic carbon, recalculated per 100 g clay. 
saturated with $\mathrm{Ba}$ (Table 2) and Ca confirm this trend. The CEC of clay fractions Ca-saturated at $\mathrm{pH} 7$ ranges from $20 \mathrm{meq} / 100 \mathrm{~g}$ clay in the surface horizon to $31 \mathrm{meq} / 100 \mathrm{~g}$ in the lowest horizons (Table 3).

\section{Mineralogy}

\section{The silt and sand fractions}

The silt fraction consists of mainly angular and subrounded quartz grains, with iron oxide specks on some of the grain surfaces. In the surface horizon about one per cent of the silt grains are amorphous silica as identified by their isotropism and low index of refraction (1.42 - 1.44). Most of these are strongly solution-pitted. Part are recognizable phytoliths (plant opal): colourless through pale pink to light brown rodlike and plate-like shapes, a few with identifiable pits, and an occasional diabolo (hour-glass) shape, sizes ranging from about $50 \mu \mathrm{m}$ to fragments a few $\mu \mathrm{m}$ across. Some amorphous silica grains were seen in the $\mathrm{Eg}$ and $\mathrm{EBg}$, and none in the $\mathrm{Bg}$ horizons.

The sand fraction throughout the profile is dominated by angular to subrounded detrital quartz grains, part locally encrusted with red iron oxides, and some grains containing very thin needle-shaped inclusions. The sand fraction from the $\mathrm{Bg} 1$ horizon (which has medium, hard ferric nodules), contains fine and very fine nodules as well. Feldspars are absent from the surface horizons, and account for varying proportions between 0.1 and 1 per cent of the fractions $50-420 \mu \mathrm{m}$ in horizons below $0.5 \mathrm{~m}$ depth. Potassium feldspars are essentially absent throughout the profile.

Epinorm mineral calculations confirm that the (sand + silt) fractions essentially consist of quartz: $98 \pm 2 \%$. Rutile contents are $0.4 \%$, decreasing in the upper three horizons to $0.2 \%$; hematite content is $0.6 \%$ in the lowest horizon, $2.7 \%$ in the $\mathrm{Bg} 1$ and $\mathrm{Bg} 2$, and steadily decreases to $0.1 \%$ in the surface horizon.

Heavy minerals constitute about $0.04 \%$ of the fraction $50-420 \mu \mathrm{m}$. Counts of 100 transparent grains per sample did not reveal significant trends with depth. The average composition is suggestive of strong weathering or preweathering: 51 zircon, 31 tourmaline, 10 rutile, 4 anatase, 4 others (including epidote, titanite, aggregates), and 38 opaque grains per 100 transparent grains.

\section{The clay fraction}

The main clay mineral is kaolinite, with soil chlorite and quartz, the latter increasing in the Apg horizons; a slight amount of feldspar; and a little goethite mainly in the $\mathrm{Bg}$ horizons. Kaolinite is dominant in the fine clay (less than $0.2 \mu \mathrm{m}$ ), and is the main component in the coarse clay. The kaolinite is b-axis disordered as indicated by the single $\mathrm{X}$-ray diffraction peak about $0.445 \mathrm{~nm}$ tailing toward smaller spacings (index of crystallization zero).

The soil chlorite has a $1.4 \mathrm{~nm}$ basal spacing not expanding with $\mathrm{Mg}$ saturation and glycerol treatment, and only collapsing to $1.0-1.2 \mathrm{~nm}$ after $\mathrm{K}$ saturation upon heating to $400{ }^{\circ} \mathrm{C}$ (surface horizon: to $550^{\circ} \mathrm{C}$ ). Only the clay fraction in the lowest horizon shows an irregular diffraction band from 1.0 to $1.4 \mathrm{~nm}$ after $\mathrm{K}$ saturation, 
Table 3. Cation exchange capacity (CEC) and iron contents of clay fractions before and after citrate extraction.

\begin{tabular}{|c|c|c|c|c|c|c|}
\hline \multirow{2}{*}{$\begin{array}{l}\text { Sample } \\
\text { No } 72 /\end{array}$} & \multicolumn{3}{|c|}{ Before citrate extraction } & \multicolumn{3}{|c|}{ After citrate extraction } \\
\hline & $\begin{array}{l}\text { CEC* } \\
\text { (meq/100 g } \\
\text { clay) }\end{array}$ & $\begin{array}{l}\mathrm{FeO} \\
(\% \mathrm{w} / \mathrm{w})\end{array}$ & $\begin{array}{l}\mathrm{Fe}_{2} \mathrm{O}_{3} \\
(\% \text { w/w })\end{array}$ & $\begin{array}{l}\text { CEC* } \\
\text { (meq/100 g } \\
\text { clay) }\end{array}$ & $\begin{array}{l}\mathrm{FeO} \\
(\% \mathrm{w} / \mathrm{w})\end{array}$ & $\begin{array}{l}\mathrm{Fe}_{2} \mathrm{O}_{3} \\
(\% \text { w/w })\end{array}$ \\
\hline 119 & 20 & 0.12 & 2.32 & 29 & 0.08 & 2.28 \\
\hline 121 & 21 & 0.10 & 3.27 & 38 & 0.08 & 3.31 \\
\hline 124 & 31 & 0.09 & 4.74 & 49 & 0.02 & 4.63 \\
\hline 127 & 32 & 0.08 & 5.53 & 49 & 0.04 & 5.49 \\
\hline
\end{tabular}

* By Ca saturation about pH 7.

collapsing to a broad peak $1.0-1.1 \mathrm{~nm}$ upon heating to $200{ }^{\circ} \mathrm{C}$.

After four one-hour treatments with hot $1 \mathrm{~N}$ neutral $\mathrm{Na}$ citrate to remove (part of) the interlayer $\mathrm{Al}$, clay fractions throughout the profile show a well-defined $1.4 \mathrm{~nm}$ peak after $\mathrm{Mg}$ and glycerol treatments. With $\mathrm{K}$ saturation, the lowest horizon shows a $1.0 \mathrm{~nm}$ peak without heating; intermediate horizons $1.4 \mathrm{~nm}$ peaks or $1.4-1.0 \mathrm{~nm}$ bands collapsing to broad $1.0-1.1 \mathrm{~nm}$ peaks upon heating to 200 $300{ }^{\circ} \mathrm{C}$, and the surface horizons the same upon heating to $400^{\circ} \mathrm{C}$.

These results suggest that the $1.4 \mathrm{~nm}$ mineral in the lowest horizon is a partially chloritized (Al interlayered) vermiculite, grading into a virtually complete soil chlorite, more resistant to citrate treatment, toward the surface. The increases in cation exchange capacity of the clay fractions after citrate treatment (Table 3) support his hypothesis. An appreciable part of the (very low) $\mathrm{FeO}$ content disappears by citrate treatment (Table 3 ), indicating that this may be ferrous iron 'trapped' in the interlayer spaces of the soil chlorite.

A study of two similar but less weathered soils from Bangladesh (Brinkman, 1977) shows Al interlayering and more trapped ferrous iron than in this profile. Kawaguchi \& Kyuma (1969) mention that aluminium interlayering, with consequent lower CEC, also occurs in clay fractions of surface soils elsewhere in Thailand.

At least some $20-25 \%$ vermiculite would be required to account for the CEC of about $50 \mathrm{meq} / 100 \mathrm{~g}$ clay in the lowest horizon after citrate treatment. (The vermiculite component would then contain about $1 \% \mathrm{MgO}$ and $2 \% \mathrm{~K}_{2} \mathrm{O}$.) Weight loss between 400 and $600{ }^{\circ} \mathrm{C}$ by thermogravimetry is about 7.9 and $5.8 \%$ for the clay of the lowest and surface horizons, respectively, equivalent to roughly 60 and $45 \%$ kaolinite. Ratios of X-ray diffraction peak areas $1.4 \mathrm{~nm} / 0.7 \mathrm{~nm}$ are roughly 0.3 , in accord with these estimates. Quartz would then account for about $10 \%$ of the clay fraction in the lowest horizon, and about $30 \%$ in the surface horizon.

Differential scanning calorimetry gave endotherms about $573{ }^{\circ} \mathrm{C}$ of $0.03 \mathrm{cal} / \mathrm{g}$ sample in the clay fraction for the lowest horizon, and $0.1 \mathrm{cal} / \mathrm{g}$ for the surface horizon. If a value of about $0.7 \mathrm{cal} / \mathrm{g}$ is taken for the quartz inversion, as found by running samples of gently crushed, coarsely crystalline quartz under the same conditions, the content of 'true' quartz (not counting less ordered surface layers) in the 
R. BRINKMAN
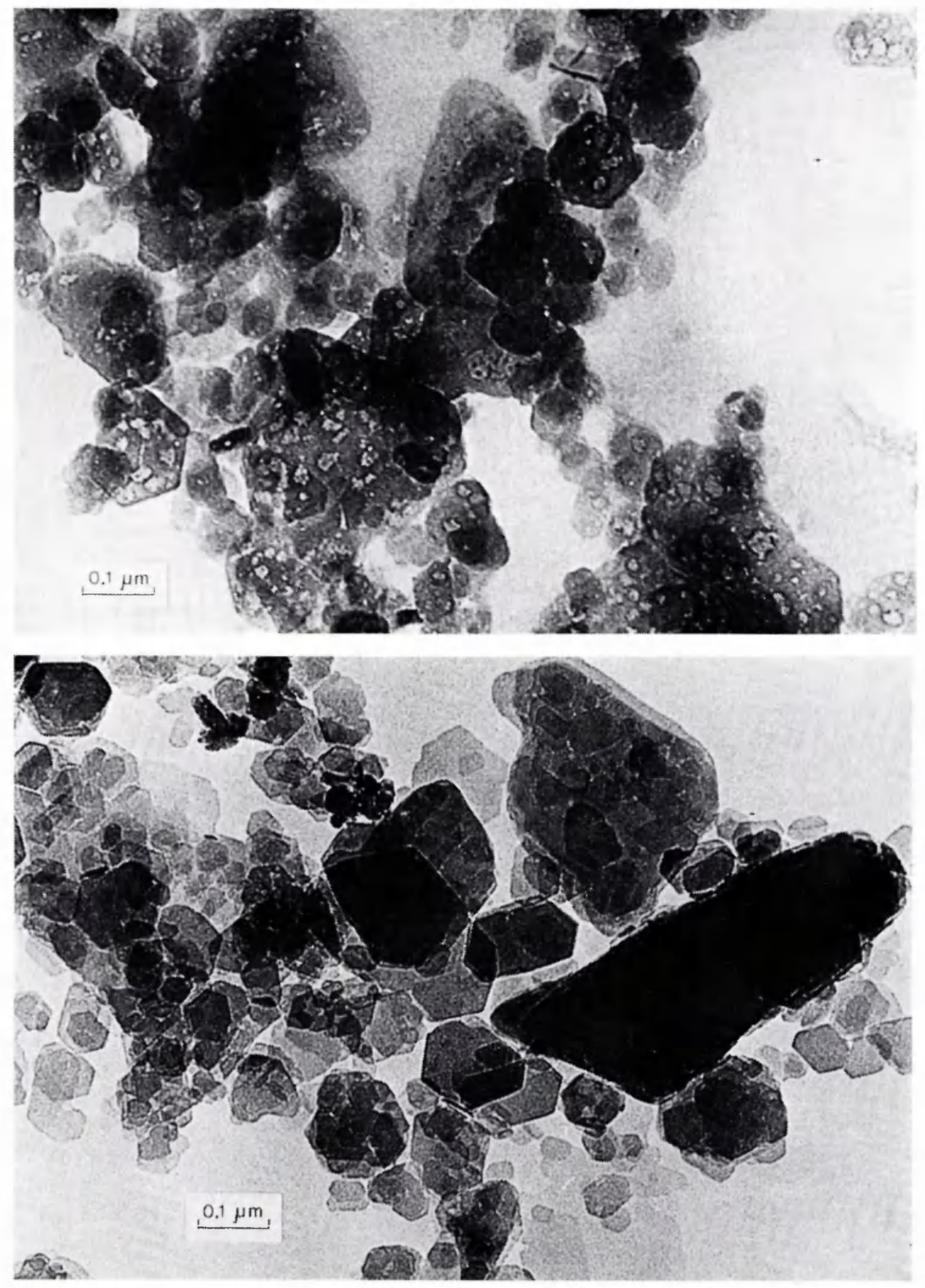

Fig. 4. Transmission electron micrographs of clay fractions. Top: Apg1 horizon; bottom: $\mathrm{Bg} 3$ horizon. 
clay fraction would be $5 \%$ for the lowest horizon, and $15 \%$ for the surface horizon. This ratio is in good agreement with the estimates given above.

Ratios of the X-ray diffraction peak heights $0.7 \mathrm{~nm} / 0.334 \mathrm{~nm}$ (kaolinite/quartz) decrease from more than 10 in the lowest horizon through 0.9 in most of the profile to 0.2 in the surface horizon. This difference cannot be explained by differences in contents alone, and part is probably due to the decreasing order and/or size of ordered domains in the clay minerals toward the surface.

Transmission electron micrographs of clay fractions (Fig. 4) also suggest pedogenic weathering of the dominant kaolinite. In the surface horizon this is "pockmarked' with dissolution cavities and has rounded edges, whereas the micrograph from the lowest horizon shows angular hexagonal forms with little indication of dissolution.

\section{Soil genesis}

\section{Hydrological aspects}

The strongly seasonal rainfall distribution and the extensive, level surface of the low terrace give rise to seasonal water saturation and shallow flooding of Roi Et and similar soils. This is augmented by the very slow permeability of horizons below some $1-2 \mathrm{~m}$ depth and of the ploughpan. The ferric iron distribution in the soil, combined with observations under saturated conditions in similar soils elsewhere (Brinkman, 1977) indicates that in the upper horizons, iron is reduced and becomes mobile during the rainy season.

During the dry season, the water-table in non-irrigated areas slowly recedes to depths ranging from about 2 to more than $3 \mathrm{~m}$. Capillary rise from the ground water into the root zone is probably negligible, therefore, as also suggested by the absence of unirrigated dry-season crops and by the virtual absence of weed growth between the rice stubble in the late dry season. These soils thus appear to be subject to seasonal water saturation, reduction and slow leaching by a solution containing ferrous iron, alternating with seasonal oxidation and, at least in the upper horizons, drying out.

\section{Geogenesis}

The parent material of the soils in the low terrace presumably was a preweathered sediment, the sand and silt fractions consisting essentially of quartz, with small to trace amounts of iron oxides, $\mathrm{Na}$ feldspars, zircon, tourmaline, rutile, anatase, etc.; and the clay fraction comprising mainly kaolinite with vermiculite, some quartz and goethite. (The clay fraction might originally have contained illite, that weathered to vermiculite by loss of $\mathrm{K}$ during an early phase of soil formation.)

The original soil material probably contained about $20 \%$ clay, and had a cation exchange capacity of about $10 \mathrm{meq} / 100 \mathrm{~g}$ mineral soil $(50 \mathrm{meq} / 100 \mathrm{~g}$ clay fraction).

\section{Pedogenesis}

Soil formation, particularly under the prevailing seasonally wet conditions, has caused drastic changes in the soil characteristics. 
An early phase of hydromorphism appears at least to have redistributed iron oxides into (hard) nodules without enclosed argillans. Biotic perforation and homogenization by roots and, at least in part, by earthworms and termites produced a system of macropores to about $1.5 \mathrm{~m}$ depth. Clay translocation, which appears to have begun after the start of homogenization and ended during the present phase of hydromorphic weathering, has lowered the clay content of the surface horizons to about half of the presumed original figure, and caused maximal clay contents in the present Eg horizon (the upper part of a former textural B horizon). This may have taken place in a drier climate than at present, with little if any water saturation or reduction.

During the present phase of hydromorphism, biotic activity has continued, as shown by the presence of abundant worm casts in, and locally on, the annually ploughed surface. Iron mobilization (reduction) and redistribution has resulted in ferric nodules and mottles enclosing argillans. The greatest changes have occurred in the nature of the clay fraction.

Vermiculite has been aluminium-interlayered, resulting in the formation of a soil chlorite, with a little ferrous iron trapped in the interlayers; and part of the kaolinite and vermiculite has been decomposed. The consequent relative accumulation of clay-sized quartz was observed both in micromorphology and clay mineralogy. The low cation exchange capacity of the clay fraction caused by these changes has resulted in a cation exchange capacity of about $1-2 \mathrm{meq} / 100 \mathrm{~g}$ soil in the surface horizon, and about $5 \mathrm{meq} / 100 \mathrm{~g}$ in the deeper horizons. Also, the deeper horizons are about $70 \%$ aluminium-saturated, the aluminium probably having originated from decomposition of the clay.

The clay mineralogy of this soil is in agreement with the hypothesis that longcontinued ferrolysis (Brinkman, 1970, 1977) has dominated soil formation. The ferrolysis model postulates that during periodic reduction, in the rainy season, iron oxides are reduced by continuing microbial decomposition of organic matter; ferrous iron then displaces exchangeable cations, which are partly leached out. When air re-enters the soil in the dry season, exchangeable ferrous iron is reoxidized to ferric hydroxide and exchangeable hydrogen. This attacks the clay minerals, releasing aluminium and magnesium from the structure which then become exchangeable cations. Part of these are removed again in the next wet season, after displacement by newly formed ferrous iron. Silica from the weakened clay structure is partly dissolved and leached; and partly reprecipitated as amorphous silica, particularly in the surface horizons that dry out periodically. Possibly, some clay-sized secondary quartz may be formed as well. Part of the exchangeable aluminium displaced by ferrous iron is not leached out, but polymerized to macro-ions with low charge during iron reduction, and fixed as interlayer fragments in the vermiculite structure. This process traps some of the originally exchangeable cations, including ferrous iron, in the interior of the interlayers.

The low percentage as well as the inactive nature of the clay make the soil very susceptible to slaking and local surface wash. Puddling of this material for rice cultivation has produced a dense ploughpan, in spite of the continuing earthworm activity. 
Consequences of this kind of soil development for use of the land include a hazard of aluminium toxicity for irrigated dryland crops with high fertilizer applications, or with rising ground water; a low buffering capacity for fertilizers and a narrow margin between aluminium toxicity and problems due to over-liming; and aeration problems in irrigated dry-season dryland crops.

\section{Acknowledgments}

I thank $\mathrm{Mr} \mathrm{A}$. Engelsma for texture analyses and separation of clay fractions; Mr L. Th. Begheijn for wet chemical analyses; Messrs J. R. M. Huting and A. J. Kuyper for X-ray fluorescence spectrometry; Miss M. Hernando for heavy mineral separation, identification and counting; Mr J. D. J. van Doesburg for X-ray diffractograms and thermal analysis; Mr H. G. Elerie of the Technical and Physical Engineering Research Service (TFDL), Wageningen, for assistance with the transmission electron microscopy; and Prof. Dr L. J. Pons, Dr S. Slager and Mr R. Miedema for their constructive and critical comments on a draft of this paper.

\section{References}

Anonymous, 1971. Pa Mong Project Phase II Reconnaissance Report, Appendix I: Land resources, Tables IV-9 and IV-10. U.S. Bureau of Reclamation, Bangkok.

Begheijn, L. Th. \& J. van Schuylenborgh, 1971. Methods for the analysis of soils used in the laboratory of soil genesis. Department of Regional Soil Science, Agricultural University, Wageningen, 156 pp.

Brinkman, R., 1970. Ferrolysis, a hydromorphic soil forming process. Geoderma 3: 199-206. Brinkman, R., 1977. Surface-water gley soils in Bangladesh. Genesis. Geoderma 17: 111-144.

Brinkman, R., A. G. Jongmans \& R. Miedema, 1977. Problem hydromorphic soils in north-east Thailand. 1. Environment and soil morphology. Neth. J. agric. Sci. 25: 108-125.

Brinkman, R. \& P. J. Dieleman, 1977. Problem hydromorphic soils in north-east Thailand. 3. Saline-acid conditions, reclamation and management. Neth. J. agric. Sci. 25 (in press). Burri, C., 1964. Petrochemical calculations based on equivalents (methods of Paul Niggli). Israel Program of Scientific Translations, Jerusalem, $304 \mathrm{pp}$.

Dümmler, H. \& D. Schroeder, 1965. (Qualitative and quantitative X-ray determination of threelayer clay minerals in soils) (German). Z. PflErnähr. Bodenk. 109: 35-47.

Halma, G., 1973. Improved efficiency in XRFS routine analysis of geochemical samples - a simple sample changer and an elegant fusion technique. Colloq. Spectroscop. int. (Firenze 1973) II: 626-631.

Kawaguchi, K. \& K. Kyuma, 1969. Lowland rice soils in Thailand. Reports on research in S.E.Asia. Nat. Sci. Ser. No 4. Center for S.E. Asian Studies, Kyoto, 270 pp.

Plas, L. van der, 1966. The identification of detrital feldspars. Developments in Sedimentology 6. Elsevier, p. 49-51.

Reeuwijk, L. P. van, 1977. A new suction apparatus for mounting clay specimens on small-size porous plates for X-ray diffraction. (in press).

Schollenberger, C. J., 1927. A rapid approximate method for determining organic matter. Soil Sci. 24: 65-68.

Schollenberger, C. J., 1931. Determining soil organic matter. Soil Sci. 31: 483-486.

Schollenberger, C. J., 1945. The determination of soil organic matter. Soil Sci. 59: 53-65. 